eine Missbildung kann ich aber die Exemplare des H. tenuifolium im Host'schen Herbar, dessen Einsicht Hr. Hofgärtner Maly bereitwilligst gestaltet hat, durchaus nicht halten, wenigstens nicht alle drei. Diese stimmen vielmehr mit $\delta$. linearifolium Neilr. überein, nur sind die Bläler fast zollbreit. Ich bin daher geneigt, das Hier. linearifolium Neilr. var. für eine schmalblättrige Form des $H$. tenuifolium Host zu halten.

Kalksburg, am 14. November 1874.

\title{
Ueber die Eucalyptus-Anpflanzung in Pola
}

\author{
Von Dr. H. Wawra.
}

Ihrem Wunsche nach, einen Bericht bezüglich der Eacalyptus globulus-Anpflanzungen in Pola zu geben, glaube ich am besten zu entsprechen, wenn ich Ihnen die direkten Mittheilungen einsende, welche mir der Herr Marinegärtner Laube darüber gemacht hat.

"Die Samen wurden auf der österreichischen Expedition durch Herrn Linienschiffskapitän v. Wiplinger acquirirt und im Herbst 1871 angebaut. - Die Sämlinge standen bis September 1873 in Töpfen, erreichten eine Höhe von 5 Fuss, wurden dann ins Freie verselzt und sind heute $12^{\prime}$ und darïber hoch. - Sie treiben bis zum Eintritt der Fröste. - Vorigen Winter hatten die Pflanzen einen 2 Monate anhaltenden Frost und eine Temperatur von bis $-7^{0}$ R. zu überstehen; jene, welche im trockenen Boden standen, hatten von der Kälte nicht gelitten; von den in feuchtem Boden befindlichen erfror die Mehrzahl und zwar knapp ober dem Boden; die letztere Erscheinung will Laube dadurch erklären, dass die Rinde des in dieser Jahreszeit noch vollsaftigen Stammes an die oberflächliche erstarrte Humusschichte anfriere; die Irrone selbst widersteht dem Frosl, daher merkt man erst im Frühjahre, dass die Kälte Unheil angerichtet hat. - Eine zweite Partie Samen wurde am 8. Dezember 1873 ausgesäet und die Sämlinge in Kisten von 1 Kub.-Fuss Rauminhalt versetzl; sie haben jetzt die Höhe von nahezu einer Klafter und werden im nächsten Jahre ins Freie verpflanzt."

Diesen Aufzeichnungen Laube's füge ich noch Folgendes bei:

Wir haben hier in Pola etwa Ein Schock junger Eucalyptusbäume; die Hälfte davon ist im Kaiserwald gepflanzt, die anderen sind im Stadtpark und noch einigen Anlagen von Pola verstrent. Die in Freien (Anlagen) befindlichen Büume scheinen besser zu gedeihen, als jene im Walde; man wählte für die letzleren elwas gelichtete, feuchte, riedrige Stellen. Einen abgestorbenen Baum sah ich nie aus der Wurzel treihen. Der Hauptstamm eines zweijahrigen Sämlings und einer einjăhrigen Planze wächst in einem Jahre um 6 Fuss und wird Einen Zoll stark, im dritten Jahre beginnt die Pflanze Ober- 
hlätter anzusetzen und hiermit scheinl das Längenwachsthum des Irauptstammes beendigt zu sein, ich sah den Baum sehr häufig im Auslande, nirgends erreicht er eine namhafte Höhe.

Die Kultur des Eucalyptus globulus ist hier zur Mode geworden und allerdings mag sein schnelles Wachsthum und das exotische Aussehen der jungen blaugrün belaubten Pflanze die Aufmerksamkeit der Gartenfreunde auf sich ziehen; doch dürften sich diese enttäuscht fühlen, wenn sie die so gewinnenden jungen Pflanzen zu einem Baum von gar tristem Aussehen aufwachsen sehen. An Stelle des saftigen blaugrünen Laubes trelen später schmutziggrïne, schmallanzettliche, schlaff herabhängende Blatter an gleichfalls herabhängenden Zweigen, der Baum gleicht dann einer Trauerweide, nur ist er lange nicht so zierlich wie diese. Ich kenne nur die kultivirten Büume, man pflanzt sie am liebsten an trockenen hochliegenden Stellen; in seiner Heimath (Neuseeland) sah ich den Baum nicht; in Europa dürften die ältesten Bäıme jene von Toulon sein, sie wurden im Jahre 1848 gepflanzt.

Für Parkanlagen dürfte sich $\boldsymbol{E}$. globulus kaum empfehlen, über seine technische Verwendbarkeit weiss ich nicht viel zu sagen. Der Slamm wird im Alter ganz verdreht und rissig und kann unmöglich ein brauchbares Bauholz abgeben. Das von diesem Gewächse gewonnene Febrifugum wird man gewiss hochschätzen lernen, sobald das sonst viel vertässlichere Chinin nicht mehr zu haben ist. Für die Bepflanzung trockener dürrer Stellen eignen sich Bäume mit horizontalen Blättern jedenfalls besser als solche mit vertikalen $(-$ ich erinnere an die trostlosen Wälder Australiens, sie machten mir immer den Eindruck, als ob sie ganz nutzlos da stünden, allerdings ist $E$. globulus laubreicher als seine austral. Verwandten). Dagegen müsste er sich für Sumpfgegenden empfehlen, nur scheint es, dass der Baum an solchen morastigen Orten nicht recht gedeihen will; jedenfalls wäre es räthlich, weitere Versuche damit anzustellen.

Pola, am 6. Dezember 1874.

\section{Reiseerinnerungen an Spanien.}

Von Moritz Winkler.

(Fortsetzung.)

Die reine trockene Luft gestattete ein schnelles Abtrocknen unserer gesammelten Schätze und eine zweite Exkursion nach Alora, einem Stadtchen oberhalb der gleichnamigen Station der Eisenbahn nach Madrid, 4 Meilen von Malaga entfernt, in reizender Lage, etwa 500 Fuss über dem Thalkessel gelegen, durch welchen die Bahn führt, und wo man hübsche Villen, saubere Gärtchen und schattige Baumgruppen findet. 